\title{
Elimination of Nickel from Aqueous Solution Using Actived Carbon and Biofilm
}

\author{
Mustapha Chabane* and Benamar Dahmani
}

Spectrochemistry and structural pharmacology laboratory, Department of chemistry, Science faculty, university of Tlemcen, Algeria

\begin{abstract}
The main of this research was to study of the efficiency of using granular actived carbon (GAC), Biofilm and biological actived carbon (BAC) columns to treat low concentration of Nickel bearing water streams and the effects of temperature and $\mathrm{pH}$ on the adsorption isotherms. Studies were conducted to delineate the effect of $\mathrm{pH}$, temperature, initial $\mathrm{Ni}$ and adsorbent concentration on adsorption of $\mathrm{Ni}^{2+}$ by $\mathrm{GAC}, \mathrm{BAC}$ and Biofilm. Breakthrough curves for removal of $0.5 \mathrm{mg} / \mathrm{L} \mathrm{Ni}{ }^{2+}$ by GAC, Biofilm and BAC columns at two contact times were plotted. Batch adsorption and column data are compared, $\mathrm{pH}$ is shown to be the decisive parameter in Ni removal for GAC but not for BAC or biofilter. Lagergren plots confirms applicability of first-order rate expression for adsorption of $\mathrm{Ni}^{2+}$ by $\mathrm{GAC}$, BAC and Biofilm. The adsorption coeficient $\left(\mathrm{K}_{\mathrm{ad}}\right)$ for BAC were 2-3 times greater than those with plain GAC. Bed Volumes of water containing $0.5 \mathrm{mg} / \mathrm{L} \mathrm{Ni}^{2+}$ treated at breakthrough for GAC, Biofilm and BAC columns were $45 \mathrm{ml}, 85 \mathrm{ml}$ and $180 \mathrm{ml}$ of Bed Volume respectively. BAC is more efficient than $\mathrm{GAC}$ in the removing of Ni from water environment.
\end{abstract}

Keywords: Nickel; adsorption; actived carbon; Biofilm

\section{Introduction}

The chronic toxicity of nickel to humans and environment has been well documented, for example, high concentration of nickel (II) causes cancer of lungs, nose and bone [1].

The drinking water guideline value recommended by World Health Organization (WHO), is $0.02 \mathrm{mg} \mathrm{Ni} / \mathrm{L}$. Low concentration (less than $2 \mathrm{mg} / \mathrm{L}$ ) of Nickel is difficult to treat economically using chemical precipitation methodologies. Ion exchange and reverse Osmosis while can guarantee the metal concentration limits required by regulatory standards, have high operation and maintenance costs [2].

Although the ability of activated carbons to remove Nickel in high concentrations from wastewater has been stablished by numerous researchers [3-9], very few articles are available on the use of activated carbon to remove Nickel in low concentration from contaminated surface or subsurface waters [10]. Activated carbon has been an effective adsorbent for the removal of many organics substances in water, its use for metal removal from water is rather rare. Several reports of Nickel removal from aqueous solutions by biosorption with micro-organism generated biomass have been published [11].

The underlying objective behind using GAC as a support for biofilm has been, therefore, to provide the foundation for remediation processes that can provide metal biosorption concurrently with removal of non-metal contaminants such as organic compounds. J.A. Scott and A. M. Karanjkar studied Nickel (in high concentration) adsorption on to Biofilm covered Granular Activated Carbon [7-11]. There is not any study on removal of low concentration of Nickel by Biofilm/GAC. The objective of this study was to investigate the adsorption characteristics of Nickel on to plain (non-biofilm) GAC, Biofilm and Biofilm/GAC , and also was to determine the effects of temperature and $\mathrm{pH}$ on the nickel uptake by plain GAC and Biofilm/GAC.

\section{Materials and Methods}

The granular activated carbon used in this study was Darco 12-20 mesh supplied by Aldrich. Carbon was washed with double distilled water and dried in an oven at $120^{\circ} \mathrm{C}$ for 24 hours. All the Nickel solutions were prepared using $\mathrm{Ni}\left(\mathrm{NO}_{3}\right)_{2} \cdot 6 \mathrm{H}_{2} \mathrm{O}$ and the solution $\mathrm{pH}$ was adjusted with $\mathrm{HNO}_{3}$ and $\mathrm{NaOH} 0.01 \mathrm{~N}$. Experimental data for the adsorption isotherms were obtained as follows.

The bacillus circulans is used as biofilm on this study which is isolated from wetland region on the north east of Algeria.

A predetermined mass of plain GAC and Biofilm/GAC were contacted with a fixed volume of a Nickel solution of known initial concentration. The nickel solution remained in contact with adsorbent untill equilibrium was reached. Batch sorption studies were performed at an ionic strength of 0.01 (added as $\mathrm{NaCl}$ ) at different temperature $\left(5^{\circ} \mathrm{C}, 15^{\circ} \mathrm{C}, 25^{\circ} \mathrm{C}\right)$ and at different $\mathrm{pH}(5,7$ and 8$)$. The contact time were selected on the basis of preliminary experiments that demonstrated that the equlibrium were stablished in 4 hours for GAC and Biofilm and 1.5 hours for Biofilm/GAC. For isotherm studies, a series of $250 \mathrm{~mL}$ Erlenmeyer flask were employed. Each Erlenmeyer flask was filled with $100 \mathrm{~mL}$ adjusted $\mathrm{pH}$ of Nickel solution of varying concentration $(0.25$ $0.5-1.0-2.5$ and $5.0 \mathrm{mg} / \mathrm{L}$ ). For each concentration 4 Erlenmeyer flask were employed. A known amount of adsorbent (plain GAC and Biofilm/GAC separately) (0.05- $0.1-0.15$ and 0.2 gr) was added in to each Erlenmeyer and agitated for the desired time periods. After this periods the solution was filtered using Glass Fiber (GF/A) filter and analysed for the concentration of the metal ions remaining in the solution by Chem Tech Alpha 4 Atomic Absorption Spectrophotometer. Conditions for the Spectrophotometer were acetylene - air flame under oxidizing conditions at $228.8 \mathrm{~nm}$ wavelengh.

Three columns including GAC, Biofilm and Biofilm/GAC were used in this study. The length of the columns was $52 \mathrm{Cm}$ and inner

*Corresponding author: Mustapha Chabane, Spectrochemistry and Structural Pharmacology Laboratory, Department of Chemistry, Science Faculty, University of Tlemcen, Algeria, Tel: 213 43213742, E-mail: chabanet2001@yahoo.fr

Received October 03, 2011; Accepted November 07, 2011; Published November 09, 2011

Citation: Chabane M, Dahmani B (2011) Elimination of Nickel from Aqueous Solution Using Actived Carbon and Biofilm. J Environment Analytic Toxicol 1:105. doi:10.4172/2161-0525.1000105

Copyright: (c) 2011 Chabane M, et al. This is an open-access article distributed under the terms of the Creative Commons Attribution License, which permits unrestricted use, distribution, and reproduction in any medium, provided the original author and source are credited. 
Citation: Chabane M, Dahmani B (2011) Elimination of Nickel from Aqueous Solution Using Actived Carbon and Biofilm. J Environment Analytic Toxicol 1:105. doi:10.4172/2161-0525.1000105

diameter of column was $14 \mathrm{Cm}$. One column was packed with 12 20 mesh sand and this column is named as biofilm column. Another column was packed with 12-20 mesh GAC.

Seeded nutrient medium $(2000 \mathrm{mg} / \mathrm{L}$ Sodium acetate as the sole carbon source, $500 \mathrm{mg} / \mathrm{L} \mathrm{NH}_{4} \mathrm{NO}_{3}, 500 \mathrm{mg} / \mathrm{L} \mathrm{KH}_{2} \mathrm{PO}_{4}, 200 \mathrm{mg} / \mathrm{L} \mathrm{CaCl}_{2}$ and $200 \mathrm{mg} / \mathrm{L} \mathrm{MgSO}_{4}$ ) was circulated (upflow , $25 \mathrm{C}, \mathrm{pH}=7$ ) for two days through GAC and sand columns.

Biofilm samples for batch biosorption test were detached and collected from the sand media. Nickel binding isotherms were produced by measuring the amount of nickel bound by biomass from solutions containing a range of Nickel concentrations. Eighty three (83) $\mathrm{mg}$ samples of biomass (dry weight) were mixed with $100 \mathrm{~mL}$ aliquots of aqueous Nickel solutions with $\mathrm{Ni}$ (II) concentrations of 0.2 $-0.5-1.0-2.0$ and $5.0 \mathrm{mg} / \mathrm{L}$. The mixtures were placed for six hours on a shaker to ensure that equilibrium was attained. The mixtures were then filtered through 0.45 -micrometer membrane filter to remove the biomass. The final concentration of unbound Nickel was determined by atomic absorption spectroscopy and the metal loading on the biomass calculated.

After two days circulating of culture medium through sand and GAC columns, the culture medium was replaced with a solution containing $0.2 \mathrm{mg} / \mathrm{L} \mathrm{Ni}$ (II) for uptake studies by Biofilm/GAC, Biofilm (sand column) and plain GAC columns. Columns were operated in the upflow mode. Effluent samples were collected from the columns and acidified and the concentration of $\mathrm{Ni}(\mathrm{II})$ was determined by atomic absorption spectroscopy.

\section{Results and Discussion}

Calculated values of correlation coefficients $\left(\mathrm{R}^{2}\right)$ at different $\mathrm{pH}$ value are given in Table 1. According to Langmuir model, reasonable straight -line correlations $\left(\mathrm{R}^{2}\right)$ were achieved for $\mathrm{Ni}(\mathrm{II})$ adsorption by GAC and Biofilm, because $\mathrm{R}^{2}$ for Langmuir isotherm were greater than for the Freundlich isotherm. For adsorption of Ni(II) by GAC/Biofilm, the correlation coefficients showed that in general the Freundlich model fitted the results better than the Langmuir model.

As illustrated in Figure 1, where adsorption isotherms of plain GAC, Biofilm and GAC/Biofilm is shown, biofilm immobilized over GAC clearly enhance the uptake of $\mathrm{Ni}(\mathrm{II})$. With regards plain GAC, $\mathrm{Ni}(\mathrm{II})$ uptake is generally low, but with biofilm immobilized over GAC particles, the $\mathrm{Ni}$ (II) uptake level can be increased 2 or 3 fold.

Figure 2 illustrates both the effectiveness of an immobilized biofilm in taking up Nickel $(0.5 \mathrm{mg} / \mathrm{L})$, along with the influence of solution temperature on equilibrium $\mathrm{Ni}(\mathrm{II})$ loading levels. That is, the presence of the biofilm, estimated at around $80 \mathrm{mg}$ (dry weight) per gram of GAC, results in a 2 to 3 fold increase in $\mathrm{Ni}$ (II) uptake when compared to plain (non-biofilm) GAC. Furthermore, over a temperature rise of $5-24^{\circ} \mathrm{C}$, the slight increase in metal uptake indicates physical adsorption, rather than metabolic activity as the prime factor in metal accumulation by the biofilm-GAC system.

The uptake of the Nickel by plain GAC increased with an increase in temperature thereby indicating the process to be endothermic.

\begin{tabular}{|l|l|l|l|l|l|l|}
\hline \multicolumn{3}{|c|}{ Langmuir Model } & \multicolumn{3}{c|}{ Freundlich Model } \\
\hline $\mathrm{pH}$ & GAC & Biofilm & GAC/Biofilm & GAC & Biofilm & GAC/Biofilm \\
\hline 5.5 & 0.92 & 0.86 & 0.66 & 0.85 & 0.83 & 0.83 \\
7.0 & 0.89 & 0.85 & 0.68 & 0.87 & 0.82 & 0.81 \\
8.0 & 0.91 & 0.88 & 0.65 & 0.84 & 0.81 & 0.85 \\
\hline
\end{tabular}

Table1: Freundlich and Langmuir isotherm correlation coefficients $\left(R^{2}\right)$ for adsorption of $\mathrm{Ni}$ (II) on GAC, Biofilm and GAC/Biofilm at different $\mathrm{pH}$.

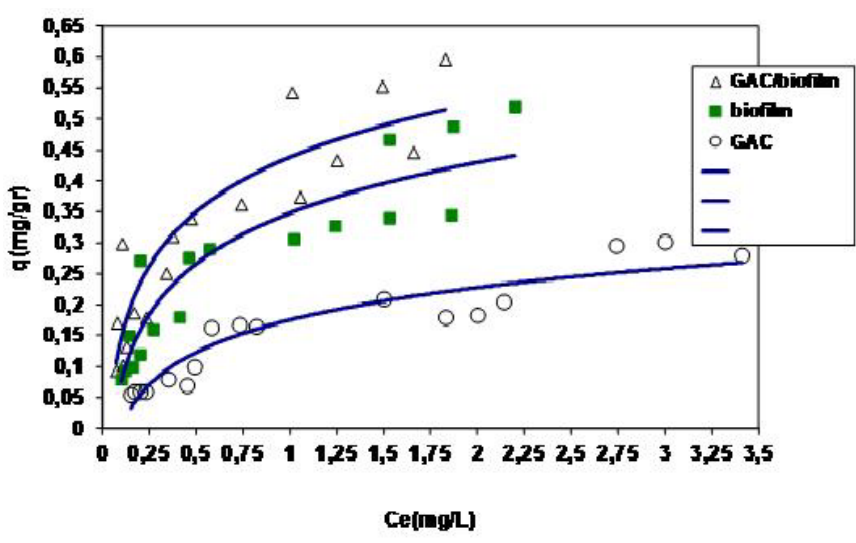

Figure 1: Isotherm plots for $\mathrm{Ni}(\mathrm{II})$ sorption by $\mathrm{GAC}$, Biofilm and GAC/Biofilm.

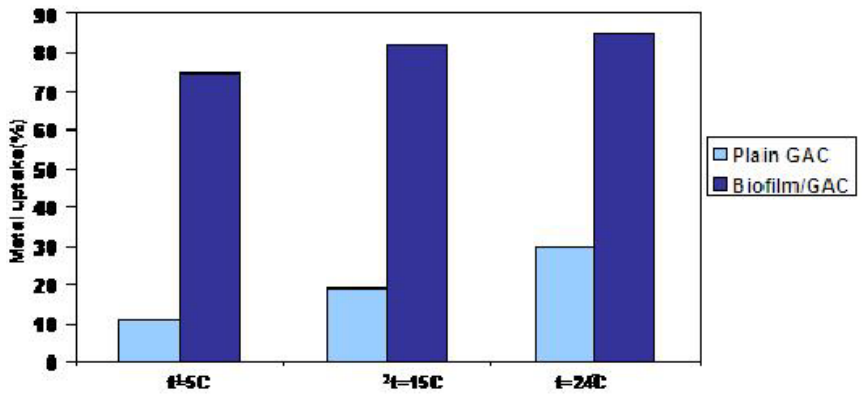

Figure 2: Effect of temperature on Nickel uptake by Biofilm /GAC and plain GAC.

Figure 3 shows the influence of solution $\mathrm{pH}$ on equilibrium uptake level. The experiments were carried out for $\mathrm{pH}$ values below the $\mathrm{pH}$ where chemical precipitation of the Nickel hydroxide occurs. In these condition, metal removal can be related only to the adsorption process. The adsorption of $\mathrm{Ni}(\mathrm{II})$ on the plain GAC increases with the increase in $\mathrm{pH}$.

The increase in $\mathrm{Ni}(\mathrm{II})$ removal as $\mathrm{pH}$ increases can be explained on the basis of a decrease in competition between proton and $\mathrm{Ni}$ (II) for the surface sites and by the decrease in positive surface charge, which results in a lower coulombic repulsion of the sorbing $\mathrm{Ni}$ (II). For the Biofilm/GAC system alkaline conditon $(\mathrm{pH}=8)$ was found to have little effect on $\mathrm{Ni}(\mathrm{II})$

The lagergren first-order rate equation is written as $\log \left(\mathrm{q}_{\mathrm{e}}-\mathrm{q}_{\mathrm{t}}\right)=$ $\log \mathrm{q}_{\mathrm{e}}-\mathrm{K}_{\mathrm{ad}} / 2.303 \mathrm{t}$.

Where qe and qt are the amount of metal adsorbed (mg/gr) at equilibrium and time " $t$ " respectively. For adsorption of $\mathrm{Ni}(\mathrm{II})$ by Biofilm/GAC, a plot of $\log \left(\mathrm{q}_{\mathrm{e}}-\mathrm{q}_{\mathrm{t}}\right)$ Vs " $\mathrm{t}$ " gives a straight line as can be seen in fig. 4 , confirming the applicability of first-order rate expression. The adsorption coefficient $\left(\mathrm{K}_{\mathrm{ad}}\right)$ for GAC, Biofilm and Biofilm/GAC were calculated from the slope of the plots separately and the values are presented in Table 2 .

The adsorption rate constants can be used for comparison between Biofilm/GAC, and GAC to adsorb Nickel from aqueous solution. The data indicates that with Biofilm/GAC, higher rate of adsorption can be achieved, because $\mathrm{K}_{\mathrm{ad}}$ for Biofilm/GAC were 2-3 times greater than those with plain GAC. 
Citation: Chabane M, Dahmani B (2011) Elimination of Nickel from Aqueous Solution Using Actived Carbon and Biofilm. J Environment Analytic Toxicol 1:105. doi:10.4172/2161-0525.1000105

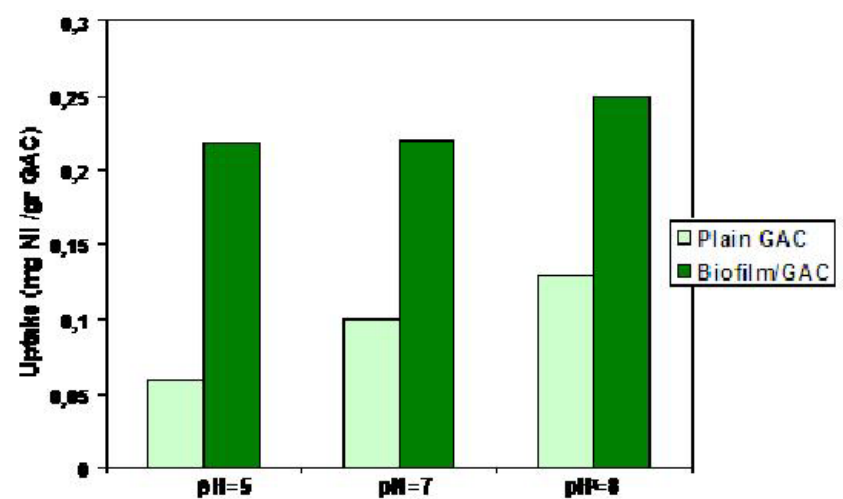

Figure 3: Effect of solution $\mathrm{pH}$ on Ni uptake by Biofilm/GAC and plain GAC

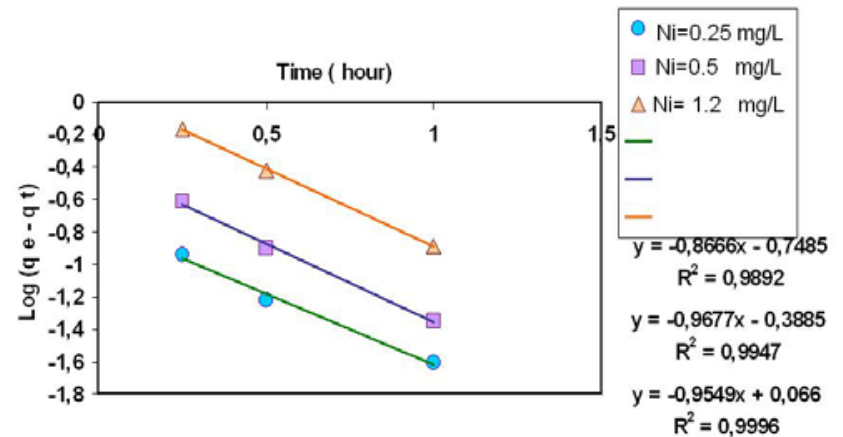

Figure 4: Lagergren plots for the adsorption of $\mathrm{Ni}(\mathrm{II})$ by Biofilm /GAC at $\mathrm{pH}=7$, adsorbent dose $100 \mathrm{mg} / \mathrm{L}$ uptake (e.g. $0.23 \mathrm{mg} \mathrm{Ni} / \mathrm{gr} \mathrm{GAC}$ at $\mathrm{pH} 6.9$ to $0.26 \mathrm{mg} \mathrm{Ni} / \mathrm{gr} \mathrm{GAC}$ at $\mathrm{pH} 8$ ), whereas $\mathrm{Ni}(\mathrm{II})$ uptake in acidic condition $(\mathrm{pH}=5)$ was the same as natural condition $(\mathrm{pH}=7.0)$.

\begin{tabular}{|l|l|l|}
\hline Ni Concentration (mg/L) & $\mathbf{K}_{\mathrm{ad}}$ Biofilm/GAC (L/Min.) & $\mathbf{K}_{\mathrm{ad}}$ GAC (L/Min.) \\
\hline 0.25 & 2.19 & 1.04 \\
0.5 & 2.22 & 1.10 \\
1.2 & 1.99 & 0.68 \\
\hline
\end{tabular}

Table 2: Calculated adsorption rate constants using GAC and Biofilm/GAC

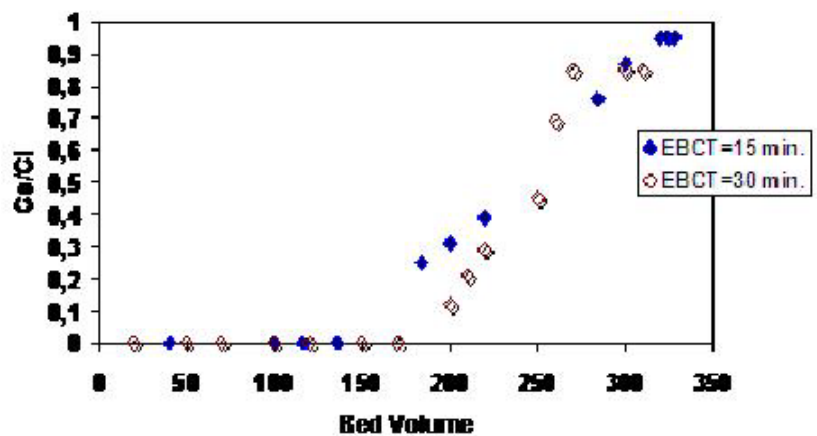

Figure 5: Breakthrough curves for $0.25 \mathrm{mg} / \mathrm{L} \mathrm{Ni}(\mathrm{II})$ at different contact time and $\mathrm{pH}=7$.

Normalized effluent Nickel concentration $\left(\mathrm{C}_{\mathrm{e}} / \mathrm{C}_{\mathrm{i}}\right)$ versus number of bed volumes (BV) treated for $0.5 \mathrm{mgNi} / \mathrm{L}$ by Biofilm/GAC column at $\mathrm{pH}=7$, are presented in Figure 5.

$\mathrm{C}_{\mathrm{e}}$ : Concentration of nickel at equilibrium in $\mathrm{mg} / \mathrm{L}$

\section{$\mathrm{C}_{\mathrm{i}}$ : Initial concentration of nickel in $\mathrm{mg} / \mathrm{L}$.}

This curve will be referred to as breakthrough curve. Breakthrough was defined at $\mathrm{C}_{\mathrm{e}}=0.01 \mathrm{C}_{\mathrm{i}}$. Breakthrough occurred at about $45 \mathrm{ml}, 85$ $\mathrm{ml}$ and $180 \mathrm{ml}$ bed volume for plain GAC, Biofilm and Biofilm/GAC columns respectively.

The removal of nickel by a GAC column was increased by $400 \%$ when biofilm immobilized over GAC particles.

\section{Conclusion}

Granular Activated carbon (GAC) is well known as an excellent adsorber of organic pollutants from contaminated water streams. GAC by itself is not in general, however, an effective adsorbent for heavy metals. Whereas, it has been shown that with a biofilm attached to the GAC surface, the uptake rate and quantity of metal ions extracted from solutions can be significantly increased. As a consequence, by immobilizing bacterial biofilms, metal removal can be combined with the adsorption of other contaminants such as organic residues.

Biosorption has the potential to provide economic metal decontamination of low concentration waste streams, but leaves the problem of metal-laden biosorbent disposal. There are, however, significant industrial and environmental process opportunities from metal impregnated over GAC surfaces, as they can usefully enhance surface activity. It is shown that it is possible to distribute metals over GAC by biosorption, through using attached biofilms. If the intention is to remove metals from contaminated streams, then ideally these biofilms should have a structure open enough not to negate the adsorption characteristics of the carbon surface for other contaminants, such as organic residues.

\section{References}

1. Halil Hasar (2003) Adsorption of nickel (II) from aqueous solution onto Activated carbon prepared from almond husk. J Hazard Mater 97: 49-57.

2. Vinod K. Gupta (1998) Equilibrum uptake, sorption dynamics,process development, and column operation for the removal of copper and nickel from aqueous solution and waste water using activated slag , a low cost adsorbent. Ind Eng Chem Res 37: 192-202.

3. Seco A, Marzal P (1999) Effect of pH, cation concentration and sorbentconcentration on cadmium and copper removalby a granular activated carbon. J Chem Technol Biotechnol 74: 911-918.

4. Corapcioglu MO, Haung CP (1987) The adsorption of heavy metals on to hydrous activated carbon. Water Research 9: 1031-1044.

5. Budinova TK, Petrov NV, Minkova VN, Gergova KM (1994) Removal of metal ions from aqueous solution by activated carbons obtained from different raw materials. J Chem Tech Biotechnol 60: 177-182.

6. Jaffar M, Ehsan U (1993) Evaluation of granular activated carbon sand based fixed bed treatment of natural waters for trace metal removal. Pak J Sci Ind Res 36: 119-122.

7. Turtureanu A, Georgescu C, Oprean L (2008) Nickel Removal from Aqueous Solutions by Flotation with Cationic Collector. Determination of the Optimum Separation Conditions. Volume 53: 1-2.

8. Scott JA, Sage GK, Palmer SJ(1988) metal immobilization by microbia capsular coatings. Biorecovery 1: 51-58.

9. Scott JA, Karanjkar AM, Rowe DL(1995) Biofilm covered Granular Activated Carbon for decontamination of streams containing heavy metals and organic chemicals. Minerals Engineering 8: 221-230.

10. Nilanjana Das, Vimala R, Karthika P (2008) Biosorption of heavy metals -An overview. Indian journal of biotechnlogie. 7: 59-169.

11. Scott JA, Karanjkar AM (1995) Adsorption isotherms and diffusion coefficients for metals biosorbed by biofilm coated Granular Activated Carbon. Biotechnology Letters 17: 1267-1270. 
Citation: Chabane M, Dahmani B (2011) Elimination of Nickel from Aqueous Solution Using Actived Carbon and Biofilm. J Environment Analytic Toxicol 1:105. doi:10.4172/2161-0525.1000105 